\title{
Evaluation of Optimal Economic Life of Cemented Carbide Tool Turning AISI4340
}

\author{
Olurotimi Akintunde Dahunsi ${ }^{\ddagger}$, Olayinka Oladele Awopetu, Tunde Isaac Ogedengbe, \\ Tiamiyu Ishola Mohammed and Taiwo Micheal Adamolekun
}

\begin{abstract}
Mechanical Engineering Department, Federal University of Technology, P. M. B. 704, Akure, Ondo State, Nigeria.
(oadahunsi@futa.edu.ng, ooawopetu@futa.edu.ng, tiogedengbe@futa.edu.ng,timohammed@futa.edu.ng,tmadamolekun@futa.edu.ng)
\end{abstract}

\begin{abstract}
¥Olurotimi Akintunde Dahunsi; First Author, Mechanical Engineering Department, Federal University of Technology, P. M. B. 704, Akure, Ondo State, Nigeria, Tel: +234 816253 9990,

tundedahunsi@gmail.com
\end{abstract}

Received: 11.01.2017 Accepted: 02.05.2017

\begin{abstract}
As turning operation proceeds on a lathe machine, it is required that sufficiently good surface quality be achieved if all the affecting parameters, including tool geometry are held constant. In this paper, the effect of tool geometry variation due to wear in the case of C6 cemented carbide tool on AISI 4340, was studied. Using surface roughness as yardstick for estimating the point beyond which the maximum economic utilization derivable from the tool is hampered, it was realized that each insert should be replaced after ten minutes of turning operation to retain their optimum usefulness. The tool wear parameters were found to be in linear relationship with the cutting time, while the average surface roughness was modelled nonlinearly using an exponential function. A fourth degree polynomial approximated the trend for the cutting force. Sharp deflections were observed on the surface roughness and cutting force graphs after the tenth minute. Generally for the entire cutting time, the measured cutting force increased by about 33\% while the flank wear width and crater wear width increased by $170 \%$ and $56 \%$ respectively. Surface roughness also increased by about $130 \%$.
\end{abstract}

Keywords Carbide tool, AISI 4340, surface roughness, tool wear, tool geometry.

\section{Introduction}

Modern manufacturing technologies calls for simultaneous improvement in control of dimensional accuracy and surface textures of machined work pieces. Surface roughness specification is often necessary on several parts to properly fulfil their required functions. For example, fatigue life, bearing properties, and wear are three major factors that make the control of surface texture important. The basic objective of finish turning of hard metals is the achievement of the best surface quality possible at the most optimal and economic tool [1, 2, 3, 4].

While the surface roughness obtained from machining the workpiece on a lathe is dependent on the workpiece material and its hardness, it is also influenced by the cutting tool material used, cutting speed, feed rate and the tool geometry (particularly, tool nose radius), the rigidity of the machine and the tool, as well as, the type and effectiveness of the cutting fluid used [5].

AISI 4340 belongs to a family of steel alloys classified as low-alloy steel, it is also refractory steel or heat resistant steel because it possess tremendous potentials for high temperature services like other refractory metals and alloys such as; Columbium, Tantalum, Tungsten, Molybdenum and so on. Finish turning process of AISI 4340 is gaining popularity because of increasing application of refractory and high hardness material. For example, hardened AISI 4340 is employed in constructing aircraft and automobile engine and transmission components. These includes; gears, cam shafts, axles and bearings. It is also employed in constructing tools, dies and molds for manufacturing operations $[6,7,8,9]$.

The economic benefits of the turning process over grinding process as finishing operation is substantial and includes; reduced cost, reduced machining time, process 
flexibility, reduced energy consumption, good prospect for dry machining (which is good for reduction of environmental pollution), high material removal rate, better compatibility with thin wall sections and complex shapes, and comparable surface finish $[6,9,10]$. Taking advantage of this benefits is possible because of the availability of superior cutting tools $[1,11]$.

Refractory metals are usually more brittle and abrasive at room temperature [12], therefore their machining often result in more rapid tool wear and relatively shorter tool life. The exceptional tool performance of cemented carbide results from their high hardness and compressive strength. For example, the lowest hardness of cemented carbide is known to be approximately the same as the highest hardness available in tool steel [5]. Carbide tools are also capable of sustaining or retaining their properties at high temperatures, in fact, repeated cycling between high and low temperatures or sustained holding at high temperature has no tempering effect on the tool within its characteristic temperature range. The tool regains its original hardness when it returns to room temperature. It functions more efficiently at high speed but requires a lot of rigidity from the machine tool $[6,10,13]$.

\subsection{Failure and wear of cemented carbide tools}

Single point carbide tools are generally preferred for high volume production machining even though they are susceptible to failure and wear, especially due to their brittle nature. Cemented carbide tools are largely used as cutting tool inserts. Such inserts interacts with chips and workpiece during cutting as shown in Figure 1 thereby resulting in the degradation of the tool.

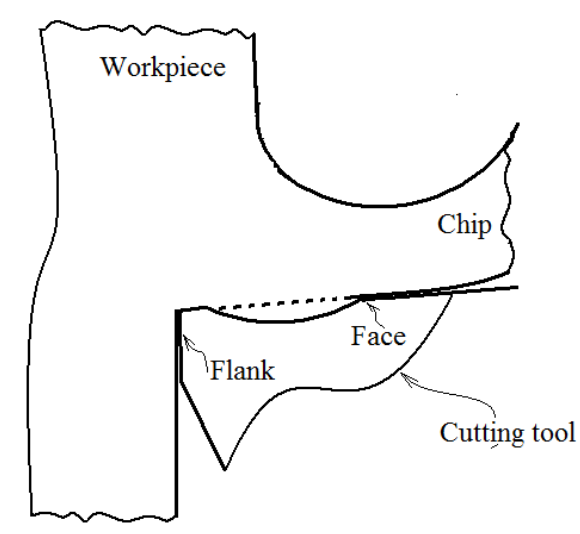

Fig. 1. Regions of tool wear in a single point cutting.

The failure of cemented carbide tools can be classified into the following two categories; failure mechanisms that brings the life of the cutting tool to an abrupt or premature end, and gradual tool wear that progressively develops on the tool flank surface (flank wear) or on the tool rake (crater wear) $[1,2,5]$. Tool failure is associated with breakdown of the cutting edge of the tool as a result of its direct contact with the workpiece. Wear could occur in these three main regions on the tool; face, flank and nose.

The wear that occurs on the tool surface over which the chip passes takes the form of a cavity and is called crater wear. Its origin is usually a distance from the cutting edge. It is the most prominent form of tool wear. The flank is the portion of the tool that is in contact with the work at the point of chip separation. Flank wear usually begins at the cutting edge and grows into a wider contact area called wearland. The surfaces that are susceptible to tool wear during machining on a lathe are shown in Figure 2.
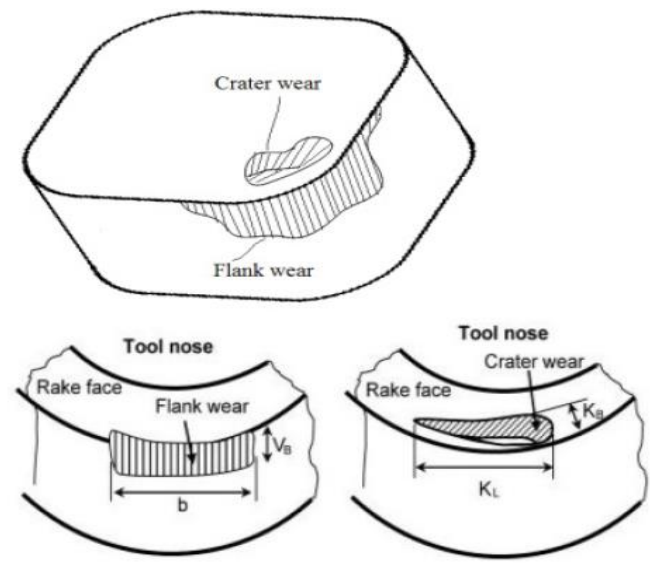

Fig. 2. Schematic of flank and crater wear and their measurements [1].

The nose wear is considered as part of the flank wear in many cases. Moreover, in operations like finish turning where the nose is in direct contact with the workpiece it is considered as a separate form of tool wear. At very high cutting conditions, as is frequently employed for cemented carbide cutting tools, the life of the tool is often determined by crater wear. If crater and flank wear occur concurrently in a balanced pattern, the tool geometry and life can be prolonged [14]. The intrinsic brittleness of cemented carbide tools make them quite susceptible to fracture and built-upedge phenomenon being usually made with intricate geometries. Therefore, little wear affects the stability of the built-up-edge which in turn affects the surface quality and degrades efficient cutting before catastrophic failure [12].

\subsection{Surface quality as criterion for determining tool failure}

Surface roughness has been the prime criterion for surface quality and a guide for acceptable fatigue strength [5]. The ideal surface roughness usually represents the best possible finishing which may be obtained for a given tool shape and feed [12]. A specified surface roughness or a desired tolerance could be used to determine or rate the acceptability of a machined workpiece. This could however be related to the level or rate of wear of the tool used if builtup-edge, chatter, inaccuracies in machine tool movement and other negative factors are eliminated.

When the good surface roughness quality is the primary goal, the tool would be said to be worn-out when the desired surface roughness can no longer be achieved with the cutting tool. It is therefore highly desirable to put the cutting tool to optimum use to reduce machining cost.

Cutting force measurements has been employed in many documented works for tool condition monitoring $[4,15,16]$. 
Recent works has shown that good prospect exist for this when combined with monitoring of other parameters like acoustic emission and vibration magnitude measurements [4, $17,18]$. Cutting force measurements in this work has been employed as a tool to confirm the point of optimal economic utilization of the tool.

\subsection{Cutting tool economic life}

Prediction of tool life during machining is essential for cutting tool design and in determination of cutting conditions and tool change strategies. It is necessary to achieve an optimized metal cutting process in which there is balance of resources. Moreover, tool wear is an unavoidable consequence of the metal cutting operation, therefore the cutting tool wear is an important factor in the economic analysis of the operation. Tool wear and its retardation have a direct relationship with the attainment of several machining optimization criteria such as minimum cost, maximum production rate and maximum profit. Catastrophic tool failure should be avoided in turning process to eliminate its associated damages to the workpiece, cutting tool and the machine tool $[2,11]$. Hence, estimation of the useful life of cutting tools is essential in finish turning process.

Usually, the tool life between tool re-sharpening or replacement is specified in one of the following ways:

1. Actual cutting time to failure,

2. Total time to failure - as with interrupted cutting process, for example, milling,

3. Length of work cut to failure,

4. Volume of metal removal to failure,

5. Number of components produced to failure, and

6. Cutting speed for a given time to failure.

Meanwhile, a cutting tool is taken to have failed when it is no longer capable of producing parts or workpieces within the required specifications. This is with little regard to the tool having justified cost before being regarded as having failed, especially for expensive tools like the carbide tools.

The point of failure and the amount of wear that caused the failure depends on the machining objective, thus, surface quality, dimensional stability, cutting forces and production rates are often used individually or in combination as criteria for establishing the point of tool failure [4, 11]. The machining cost increases due to increase in the number of operations involved.

It is however pertinent that tools be changed just when they attain an appropriate wear level to maintain the required level of surface finish. This must be done in a way that it result in reduced tool change time, loss in production time due to stoppage, as well as the overall machining cost. It is a general rule that on the production run, the higher cost of carbide tooling pays dividends, while on the short run, it may not be justified [4].

A cutting tool would be said to be worn-out at the point when it can no longer be used to obtain the surface roughness specification required. Cost of machining increases with decrease in surface roughness of the machined product. The acceptable level of surface roughness is relative, therefore the focus of this work is to estimate the optimum life of the carbide tool employed in machining AISI 4340 workpiece in minutes.

\section{Materials and Method}

The finish turning experiment was performed using a three jawed self-centering Cholchester center lathe machine. The workpiece material was AISI 4340 steel with an initial diameter of $93.98 \mathrm{~mm}$. the square shaped carbide tool used belonged to the ANSI classification of general purpose cutting tool, C6 with ISO equivalent P30. All the cutting parameters were held constant during the experiment. C6 is recommended by the American Society for Metals (ASM) for working on steel materials whose Brinnel hardness number reaches BHN 330 [5, 9, 19, 20]. The tool's HRA hardness value and density are $91.3 \mathrm{Ra}$ and $13.84 \mathrm{~g} / \mathrm{cm}^{3}$ respectively and the tool angles were $-6^{\circ},-6^{\circ}, 6^{\circ}, 6^{\circ}, 15^{\circ}$ and 0.6. The turning parameters are listed in Table 1 while the chemical composition of the tool is given in Table 2 .

Table 1. Turning Parameters

\begin{tabular}{|l|l|}
\hline Parameter & Value \\
\hline Cutting speed & $2.8 \mathrm{~m} / \mathrm{s}$ \\
\hline Feed & $3 \mathrm{~mm} / \mathrm{rev}$ \\
\hline Depth of cut & $1.30 \mathrm{~mm}$ \\
\hline Cutting condition & Dry \\
\hline
\end{tabular}

Table 2. Chemical composition of the Carbide tool (wt\%)

\begin{tabular}{|l|l|l|l|l|}
\hline $\begin{array}{l}\text { Chemical } \\
\text { compound }\end{array}$ & CO & TiC & Tac & WC \\
\hline $\begin{array}{l}\text { Percentage } \\
\text { content }\end{array}$ & 3.0 & 3.0 & 7.0 & 82.0 \\
\hline
\end{tabular}

The surface roughness, maximum flank wear width and maximum crater wear width were measured after every sixty seconds cutting time using the toolmaker's microscope. The microscope was set to magnification factor $\mathrm{x} 125$ and $\mathrm{x} 200$ since it had the capacity of serving as a comparator whereby views could be superimposed. Kistler's three component piezo-electric dynamometer mounted on the cross-slide of the lathe machine was used for the cutting force measurement. Measurements were made and recorded for twenty cutting operations (that is, twenty minute total cutting time and one minute for each cutting operation).

After the $13^{\text {th }}$ minute, the cutting process started getting noisy having reached the galling stage where the material particles were welded to the machine surface signaling an onset of critical tool wear. When working on AISI 4340 steel, C6 is not recommended for more than $3 \mathrm{~mm}$ depth of cut [20]. The chemical composition of the work material is presented in Table 3. 
Table 3. Chemical composition of AISI 4340 steel (wt\%)

\begin{tabular}{|l|l|l|l|l|l|l|l|}
\hline Alloy elements & $\mathrm{C}$ & $\mathrm{Mn}$ & $\mathrm{Si}$ & $\mathrm{Cr}$ & $\mathrm{Ni}$ & Mo & Fe \\
\hline Percentage content & 0.40 & 0.75 & 0.28 & 0.80 & 1.80 & 0.20 & Remainder \\
\hline
\end{tabular}

\section{Results and Discussion}

\subsection{Statistical analysis}

Significant impact of cutting speed, feed rate and depth of cut on the surface roughness and tool wear during turning process has been established in previous works [3, 12, 19, 21 - 23]. These parameters were held constant in this work to enable a relationship to be established between the rate of tool wear, cutting force and workpiece surface roughness.

Mathematical model relating the parameters were obtained using regression analysis in MINITAB 14 and Microsoft Excel 2007 with the Solver tool. The relationship between the cutting parameters is as given in Equation 1.

$$
S=f(F, V B, K T)
$$

where $\mathrm{S}$ represents workpiece surface roughness measurements in millimeters, F represents the average resultant cutting force measured in Newtons, VB represents flank wear measured in millimeters and KT represents the crater wear measured in millimeters as well. A summary of the regression statistical output is presented in Table 4 and 5.

Table 4. Summary of the general regression analysis output data

\begin{tabular}{|l|c|}
\hline Regression parameter & Value \\
\hline $\mathrm{R}^{2}$ & 0.8955 \\
\hline Adjusted $\mathrm{R}^{2}$ & 0.8759 \\
\hline Standard error & 0.0006 \\
\hline Significance of $\mathrm{F}$ & $4.5341 \times 10^{-8}$ \\
\hline Number of observations & 20 \\
\hline
\end{tabular}

Table 5. Other regression analysis output data

\begin{tabular}{|l|c|c|c|c|c|}
\hline & Coefficients & Standard error & $\mathrm{t}$ - stat & $\mathrm{P}$ - value & Lower 95\% \\
\hline Intercept & $-1.1114 \times 10^{-2}$ & $3.23 \times 10^{-3}$ & -3.4478 & $3.3086 \times 10^{-3}$ & $-1.7985 \times 10^{-2}$ \\
\hline Cutting force, F & $1.5362 \times 10^{-4}$ & $3.211 \times 10^{-5}$ & 4.7840 & $2.0285 \times 10^{-4}$ & $8.5548 \times 10^{-5}$ \\
\hline Flank wear, VB & $-6.7590 \times 10^{-2}$ & $9.7736 \times 10^{-2}$ & -0.6916 & 0.4991 & -0.2748 \\
\hline Crater wear, KT & $3.6566 \times 10^{-2}$ & $3.0121 \times 10^{-2}$ & 1.2139 & 0.2423 & $-2.7290 \times 10^{-2}$ \\
\hline
\end{tabular}

Equation 2 is computed from coefficients in Table 5, while a graph comparing the measured and predicted surface roughness measurement is presented in Figure 3. Residuals resulting from the comparison in Figure 3 are shown in Figure 4. Except for the first cutting operation where the residual was large the others were within a arrange of about $\pm 6 \times 10^{-4} \mathrm{~mm}$.

$$
\begin{gathered}
S=1.1114 \times 10^{-2}+1.5362 \times 10^{-4} \\
-6.7590 \times 10^{-2} V B \\
+3.6566 \times 10^{-2} K T
\end{gathered}
$$

\subsection{Surface roughness}

Figure 5 presents an exponential trend relationship between the surface roughness of the machined workpiece and the cutting time. The trend is also mathematically by $R_{a}=3.642 \times 10^{-1}+4.776 \times 10^{-5} e^{0.2403 t}$. The curve began to deflect upwards around the tenth minute signifying a sharp increase in the rate of change of the surface roughness from the eleventh minute onwards. 


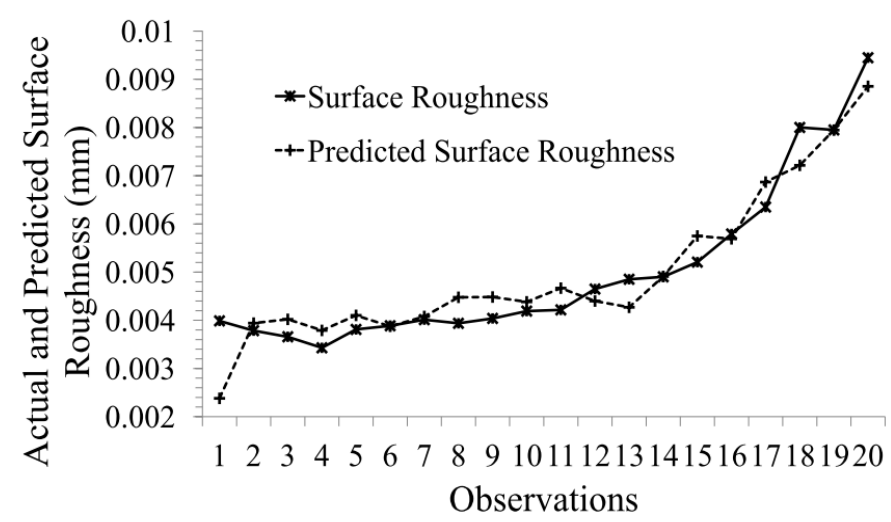

Fig. 3. Measured and predicted machined surface roughness.

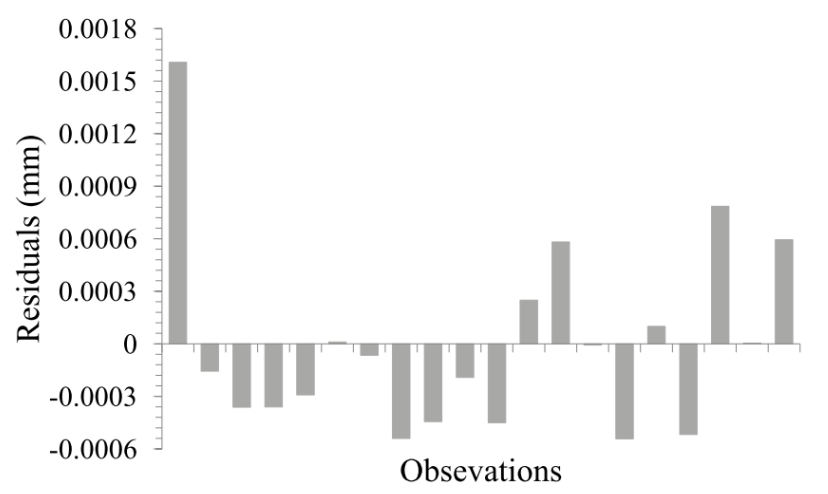

Fig. 4. Deviation of the predicted surface roughness values from the measured values.

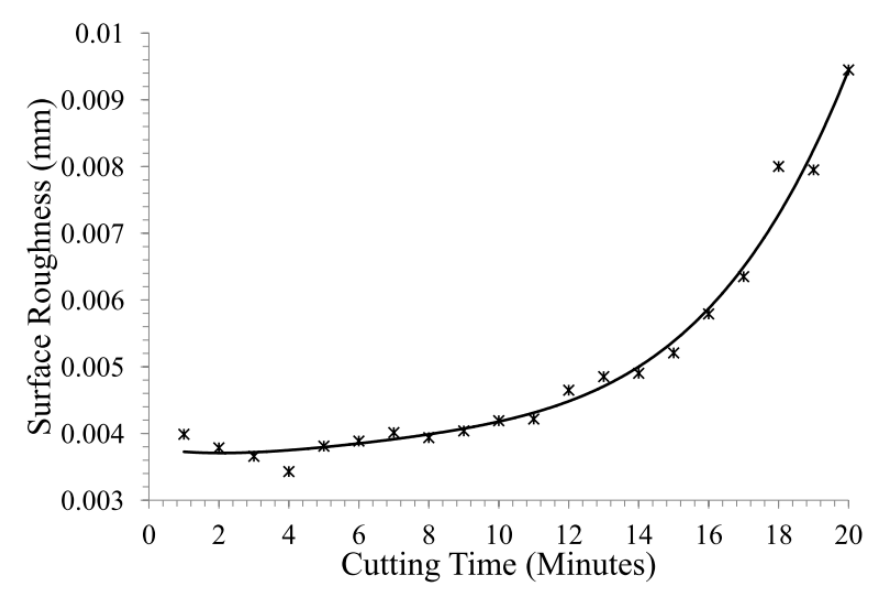

Fig. 5. A graph of surface roughness against time.

The surface roughness of a work material primarily depends on the feed and cutting tool geometry, but since a constant feed was used in this experiment, the change in the geometry of the tool as a result of wear must be responsible for the change in the surface roughness of the work material. Consequently, if surface roughness is considered as the primary factor in assessing the tool life in this experiment it would be economical to have changed the cutting tool at the tenth minute of the cutting operation even though it was yet far from the maximum permissible wear values prescribed in standards.

\subsection{Flank and crater wear}

Flank and crater wear progressed in linear trends as shown in Figure 6. The pattern and range of values are normal and expected. Moreover, the ratio of the highest value measured for the maximum flank wear width to the lowest was about 2.75 , while the flank wear grew at a rate of about $0.0014 \mathrm{~mm} / \mathrm{min}$. The ratio of the highest value measured for crater wear to the lowest was about 1.56 and the wear parameter grew at a rate of $0.005 \mathrm{~mm} / \mathrm{min}$.

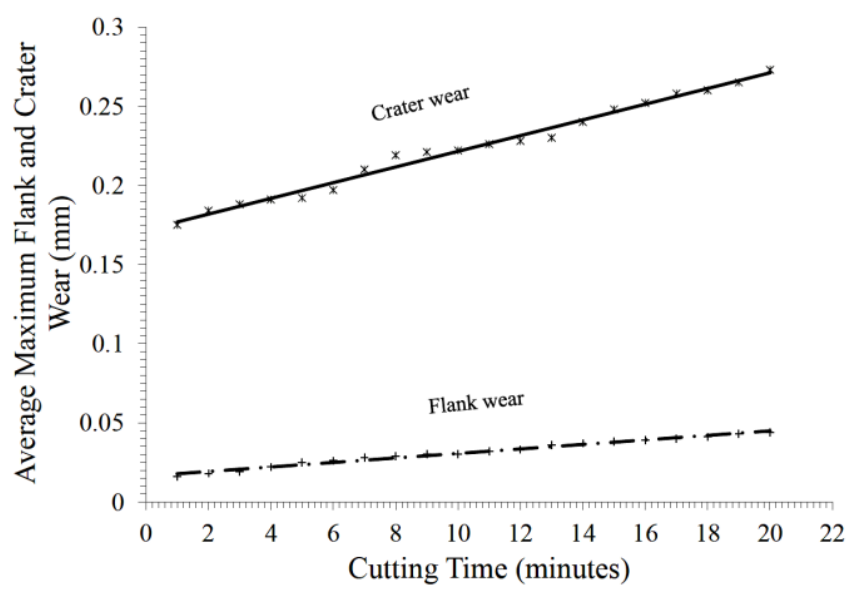

Fig. 6. Progress of maximum flank and crater wear with the cutting time.

When the cutting edge of the carbide tool insert used was compared with the cutting edge of a new tool under the toolmaker's microscope, a maximum flank wear depth of $0.013 \mathrm{~mm}$ and a maximum crater wear depth of $0.01 \mathrm{~mm}$ was revealed in the used tool, this shows a ratio of 1:3 in favour of the flank wear.

The maximum flank wear and the maximum crater wear measured were however found to be significantly less than the stipulated maximum permissible wear of $0.55 \mathrm{~mm}$ and $0.25 \mathrm{~mm}$ respectively $[11,22,24]$ but the rate of surface degradation started to get serious at about the $10^{\text {th }}$ minute of the experiment. Figure 6 also shows that crater wear was more dominant. This signifies that the principal tool wear process was diffusion between the cutting tool and the chips. Composition of the carbide tools has been known to make them readily predisposed to diffusion wear [1, 2, 19, 22].

Moreover, this is corroborated by Zhang and others [25] as well as Aslantas and others [1] in their work which made case for coated ceramic tool inserts. Chemical reactions (related to diffusion wear) and high temperature (due to low thermal conductivity of the cutting tool) combined with high stress values in the cutting region combined to give rise to the crater wear formation [11]. With further deterioration, the crater wear reaches the tool tip and fracture occurs, thereby modifying the tool geometry as shown in Figure 7. 


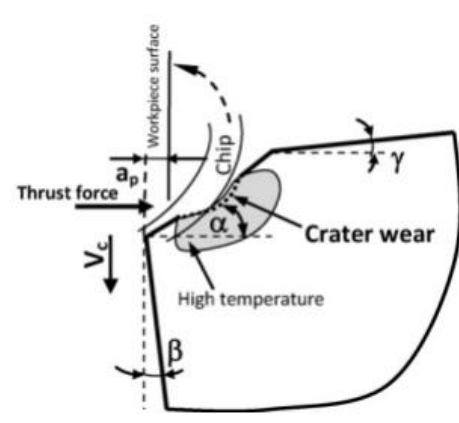

$\mathrm{v}_{\mathrm{c}}$ : Cutting speed
$\mathrm{a}_{\mathrm{p}}$ : Depth of cut
$\mathrm{r}_{\mathrm{u}}$ : Chip up-curl radius
$\beta$ :Clearance angle
$\alpha$ :Chamfer angle
$\gamma:$ Negative rake angle
$\mathrm{q}_{\mathrm{t}}:$ Heat flow to the
cutting tool
$\mathrm{T}_{\mathrm{i}}:$ Tool-chip interface
temperature

Fig. 7. Crater wear favoured chip curling pattern [1].

\subsection{Cutting Force}

Although the trend for the cutting force could best be modelled with a fourth degree polynomial given by,

$y=-0.0012 x^{4}+0.0662 x^{2}-1.1169 x^{2}$ $+6.8907 x+49.419$

as shown in Figure 8. Its increase can be said to approximately correlate with the increase in surface roughness of the workpiece linearly as shown in Figure 9. This was achieved with a coefficient of determination, $R^{2}$ of 0.9644. The prominence of the second turning point which occurred at about the $11^{\text {th }}$ minute also approximately agree with the observation of $10^{\text {th }}$ minute turning point in Figure 5.

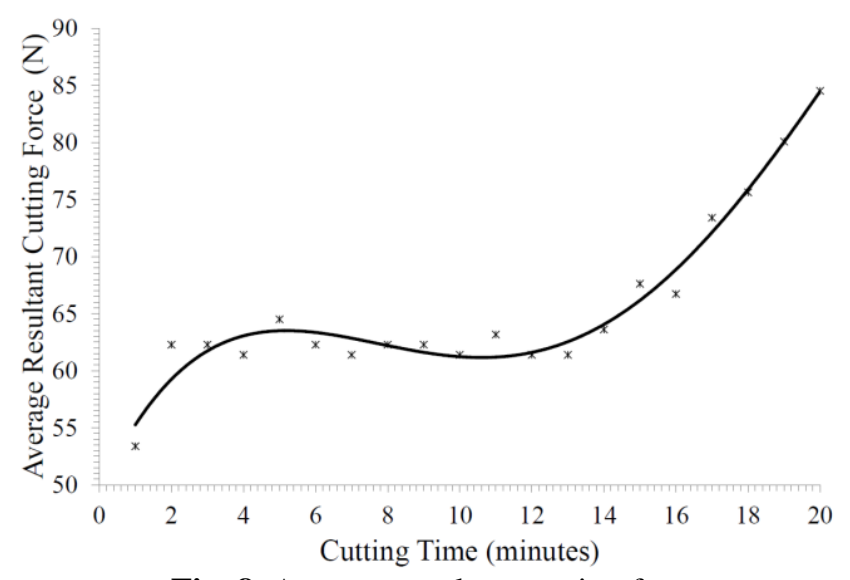

Fig. 8. Average resultant cutting force.

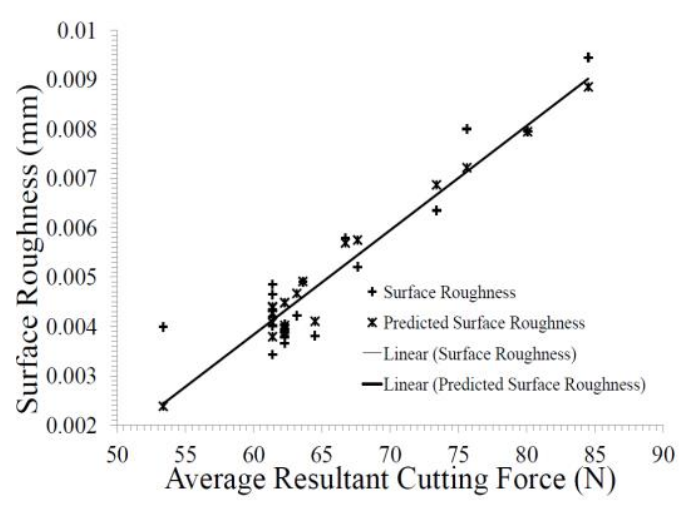

Fig. 9. Correlation of surface roughness with the cutting.

\section{Conclusion}

In-process tool monitoring and measurement has been employed in determining the optimal economic life of the cemented carbide tool turning AISI4340. The trend for the increase in the flank and crater wear was linear while the trend for the surface roughness followed an exponential growth in conformity with documented patterns in the literature. The workpiece surface roughness was found to deteriorate beyond acceptable level after the $10^{\text {th }}$ minute of the turning process.

\section{Acknowledgements}

The authors wish to acknowledge the immeasurable assistance received from Mr M. L. Olawuyi as well as the University of Detroit, Michigan.

\section{References}

[1] Aslantas, K., Ucun, I., and Cicek, A.: Back Propagation Algorithm: The Best Algorithm Among the Multi-Layer Perceptron Algorithm, International Journal of Computer Science and Network Security IJCSNS, 9, 442-451, 2009.

[2] Astakhov, V. P. and Davim, J. P.: Tools (Geometry and Material) and Tool Wear, in: Machining Fundamentals and Recent Advances, edited by Davim, J. P., Springer Verlag Publisher, London, 2008.

[3] Mandal, N., Doloi, B., and Mondal, B.: Predictive Modeling of Surface Roughness in High Speed Machining of AISI4340 Steel Using Yttria Stabilized Zirconia Toughened Alumina Turning Insert, International Journal of Refractory Metals and Hard Materials, 38, 40-46, 2013.

[4] Kayhan, M. and Budak, E.: An Experimental Investigation of Chatter Effects on Tool Life, Journal of Engineering Manufacture - Proceedings of the Institute of Mechanical Engineering (IMechE), 223, 1455-1463, 2009.

[5] Lyman, T.: Metals Handbook, American Society of Metals, Metals Park, Ohio 44073, 8th edn., 1997.

[6] Shihab, S. K., Khan, Z., Mohammad, A., and Siddiquee, A.: A Review of Turning of Hard Steels Used in Bearing and Automotive Applications, Production and Manufacturing Research: An Open Access Journal, 2, 24-49, 2014.

[7] Josh, A. and Rampal, R.: Effect of Cutting Parameters on Tool Wear of Coated Carbide Tool in Hard Turning of AISI4340, International Journal of Engineering Sciences and Research Technology, 3, 112-117, 2014.

[8] de Lima, J., de Avila, R. F., and Abrao, A. M.: Turning of Hardened AISI 4340 Steel Using Coated Carbide Inserts, Proceedings of Institution of Mechanical Engineering: Engineering Manufacture, 221, 1359-1366, 2007.

[9] Suresh, R., S. Basavarajappa, V. N. G., and Samuel, G. L.: Machinability Investigations on Hardened AISI 4340 Steel Using Coated Carbide Insert, International Journal 
of Refractory Metals and Hard Materials, 33, 75-86, 2012.

[10] Coelho, R. T., Ng, E., and Elbestawi, M. A.: Tool Wear When Turning Hardened AISI 4340 with Coated PCBN Tools Using Finishing Cutting Conditions, International Journal of Machine Tools and Manufacture, 47, 263-272, 2007.

[11] Arsecularane, J. A., Zhang, L. C., 10 and Montross, C.: Wear and Tool Life of Tungsten Carbide, PCBN and PCD Cutting Tools, International Journal of Machine Tools and Manufacture, 46, 482-491, 2006.

[12] Wilson, F. W.: Fundamentals of Tool Design, Prentice-Hall of India Private Limited, New Delhi, India, 1997.

[13] Johnson, J. L., Runyon, G., and Morton, C.: Powder Power, Cutting Tool Engineering, 60, 112-117, 2008.

[14] Astakhov, V. P.: The Assessment of Cutting Tool Wear, International Journal of Machine Tools and Manufacture, 44, 2004.

[15] Ezugwu, E. O., Olajire, K. A., and Bonney, J.: Modelling of Tool Wear Based on Component Forces, Tribology Letters, 11, 55-60, 2001.

[16] Awopetu, O. O., Dahunsi, O. A., and Aderoba, A. A.: Selection of Cutting Tool for Turning _ - Titanium Alloy BT5, Assumption University Journal of Technology, 9, 46-52, 2005.

[17] Bhuiyan, M. S. H., Choudhury, I. A., and Dahari, M.: Monitoring the ToolWear, Surface Roughness and Chip Formation Occurrences Using Multiple Sensors in Turning, Journal of Manufacturing Systems, 33, 476487, 2014.
[18] Yaldiz, S. and Unsacar, F.: A Dynamometer Design for Measurement the Cutting Forces on Turning, Measurement, 39, 80-89, 2006.

[19] Sahoo, A. K. and Sahoo, B.: Experimental Investigation on Machinability aspects in Finish Hard Turning of AISI4340 Steel Using Uncoated and Multilayer Coated Carbide Inserts, Measurement, 45, 2153-2165, 2012.

[20] Davies, J. R.: Metals Handbook, American Society of Metals, Metals Park, Ohio 44073, desk edn., 1998.

[21] Hughes, J. I., Sharman, A. R. C., and Ridgway, K.: The Effect of Cutting Tool Material and Edge Geometry on Tool Life and Workpiece 30 Surface Integrity, Journal of Engineering Manufacture: Proceedings of the Institute of Mechanical Engineers, 220, 93-107, 2006.

[22] Li, B.: A Review of Tool Wear Estimation Using Theoretical Analysis and Numerical Simulation Technologies, International Journal of Refractory Metals and Hard Materials, 35, 143-115, 2012.

[23] Babu, B. V. and Karthik, S.: Genetic Programming for Symbolic Regression of Chemical Process Systems, Engineering Letters, 14, 1-14, 2007.

[24] Werner, K. A.: In-Process Monitoring of Cutting Tool Forces, Biennial International Machine Tool Technical Conference, 4, 11.83-11.99, 1984.

[25] Zhang, S., J. F. Li, J. X. D., and Li, Y. S.: Investigation on Diffusion Wear During High-Speed Machining Ti-6Al-4V Alloy With Straight Tungsten Carbide Tools, International Journal of Advanced Manufacturing Technology, 44, 17-25, 2009. 